\title{
THE ROLE OF LOGISTICS SERVICE PROVIDERS IN ENHANCING CORPORATE ENVIRONOMENTAL RESPONSIBILITY IN SUPPLY CHAINS [1]
}

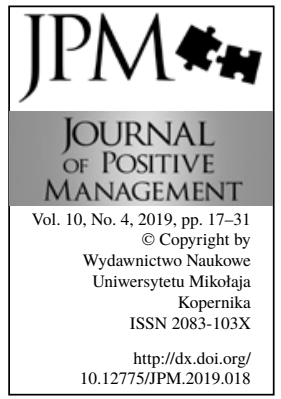
Barbara Ocicka

SGH Warsaw School of Economics, Warsaw, Poland

e-mail: barbara.ocicka@sgh.waw.pl

\begin{abstract}
Purpose: The purpose of this paper is to evaluate the role of logistics service providers (LSPs) in environmental performance improvement of transport processes in chemical supply chains.

Methodology: Lessons learnt are derived from the Interreg Central Europe Project ChemMultimodal, in which 59 companies in Central Europe (including 5 in Poland) tested transport modal shifts. The author presented 5 case studies of transport practices developed by chemical companies operating in Poland. Each case study is based on in-depth and detailed examination of a particular transport process using the ChemMultimodal toolbox.

Findings: The role of LSPs as architects of transport processes as well as integrators of transport modes and connections is crucial for rising environmental effects in chemical supply chains. As a result of collaborative outsourcing, the potential of $\mathrm{CO} 2$ emissions reduction by app. $60 \%$ is really significant in transport management of chemical products.
\end{abstract}

Originality/value: An in-depth analysis based on case studies of chemical companies sheds light on the value delivered by integrating LSPs into corporate environmental responsibility in supply chains. Conclusions drawn for the significance of environmental impacts of multimodal transport in chemical supply chains can be a good reference point for logistics managers in diverse industries.

Keywords: corporate environmental responsibility, outsourcing, transport, $\mathrm{CO} 2$ emission, chemical industry

Paper type: Research paper

\section{Introduction}

The achievement of a balance between economic, environmental and social effects is a long-term objective to make development sustainable to ensure that it meets the needs of the present without compromising the ability of future generations to meet their own needs (World Commission on Environment and Development, 
THE ROLE OF LOGISTICS SERVICE

Barbara Ocicka
1987). Sustainability issues has been an area of growing concern and attention for companies, especially operating on a global scale, that more and more often develop strategies of sustainable supply chain management (SCM). Carter and Rogers (2008) defined sustainable SCM as the strategic, transparent integration and achievement of an organisation's social, environmental and economic goals in the systematic coordination of key interorganisational business processes for improving the long-term economic performance of the individual company and its supply chains. Nowadays, such logistics and SCM trends are mostly affecting the sustainability, as: globalization, relationships and outsourcing, technology and lean or agile strategies (Grant et al., 2015). Companies more frequently assess the influence of their supply chains on the environment and measure overall carbon dioxide $(\mathrm{CO} 2)$ emissions resulting from their business activities.

In the journey towards a sustainable development, the international community agreed on the need to drastically reduce world greenhouse gas (GHG) emissions (European Commission 2011). The World Economic Forum (2009) estimates that the logistics and transport sector accounts for 2,800 megatonnes of $\mathrm{CO} 2 \mathrm{e}$ emissions annually or 5.5\% of the total 50,000 mega-tonnes $\mathrm{CO} 2 \mathrm{e}$ generated by human activity. It also estimated that most of the carbon emissions from logistics are caused by freight transport (Grant et al., 2015). The transport sector makes up $27 \%$ of the total greenhouse gas emissions in the United States (U.S. Department of State, 2016) and 24\% of GHG emissions in the EU-28 (Eurostat, 2018). Among key initiatives towards a competitive and resource-efficient transport system in the EU economy, the following points are indicated: the development of multimodal freight transport corridors, designing sustainable transport networks and usage of the $\mathrm{CO} 2$ calculators on a regular basis (European Commission, 2011).

The author devotes attention to multimodal transport management and presents results of the research carried out within the Interreg Central Europe Project ChemMultimodal [2] over the period 2016-2019. The purpose of this paper is to evaluate the role of logistics service providers (LSPs) in environmental performance improvement of transport processes in chemical supply chains. The data are taken from the project's pilots phase, in which 5 chemical companies selected routes for modal shift and tested multimodal transport solutions in cooperation with their LSPs. The quantitative analysis of emissions is carried out using the ChemMultimodal $\mathrm{CO} 2$ calculator [3].

\section{Significance of integration and coordination in multimodal transport development}

According to the European Combined Transport Directive (92/106/EEC) [4], multimodal transport is transport where the goods or passengers are transported by 
multimodal transport, where the cargo carried is loaded into a single loading unit for the entire duration of the journey, which is transshipped from one mode of transport combination of at least two modes of transport in a single transport chain, without a change of container for the goods, with most of the route travelled by rail, inland waterway or ocean-going vessel and with the shortest possible initial and final journey by road (Macharis et al., 2012). There is still a need to develop initiatives aiming at better exploitation of intermodal transport potential in the EU countries. In regards to the White Paper titled "Roadmap to a Single European Transport Area - Towards a competitive and resource efficient transport system", 30\% of road freight over $300 \mathrm{~km}$ should shift to other modes such as rail or waterborne transport by 2030, and more than $50 \%$ by 2050 (European Commission, 2011). Despite all efforts, the statistics show that the introduction of more environmentally sustainable transport modes has been slow, rail and inland waterborne transport still account for about $12 \%$ and 4\%, respectively of all transports (Bask and Rajahonka, 2017). One of the reasons is that logistics structures and company decision making have not favoured CO2 efficient freight transportation (Pålsson and Johansson, 2016).

As Flodén et al. (2017) pointed out, development of intermodal transport requires coordination of activities and integration of resources between all engaged parties. Main actors participating in intermodal transport processes are: freight forwarders, hauliers and terminal operators, that deliver a joint service to parties of trade transactions. Three just mentioned elements: actors, activities and resources co-create a system of intermodal transport (Figure 1).

System management is crucial to make an intermodal network effective, reliable and safe. The nature of intermodal networks is being influenced by a range of diverse internal and external forces and conditions, like e.g.: production and administrative systems, infrastructure, demand for transport services, competitiveness of single-mode transportation or law and regulations. Complexity of intermodal transport systems management determines core competences of intermodal network providers - intermediary companies that coordinate the shippers' needs with the physical (rail) operations performed by the (rail) operators (Monios and Bergqvist, 2017). Logistics service providers often play the role of intermodal network providers through integrating transport modes and connections as well as orchestrating intermodal systems.

Collaboration in transport management helps to minimise some of the inefficiencies in supply chains, among others: high inventory carrying costs, unproductive waiting time, high transport costs, lack of critical network mass, empty running kilometres, long cycle times, poor on time performance (Sutherland, 2003; Mason et al., 2007). There are some advantages of a collaborative approach for transport management due to integration of supply chain partners on both horizontal and vertical levels (Figure 2) derived from such initiatives like e.g.: 
THE ROLE OF

LOGISTICS

SERVICE

Barbara Ocicka

Figure 1.

A conceptual model of an intermodal transport system

Source: Flodén et al., 2017.

Figure 2.

Conceptual

framework linking

distribution

characteristics, intermodal transport provision and the role of integration

Source: Monios and

Bergqvist, 2017.

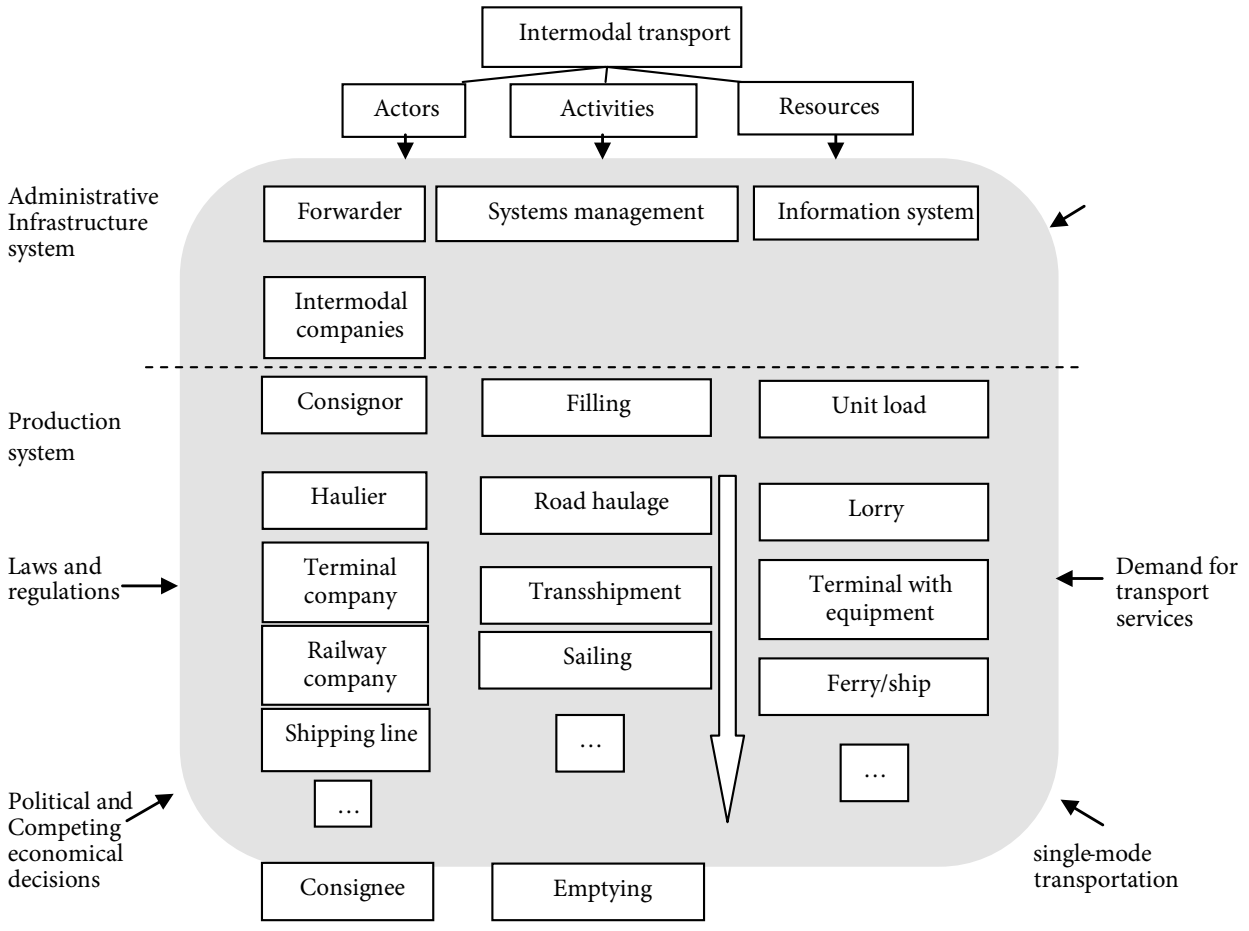

Horizontal integration

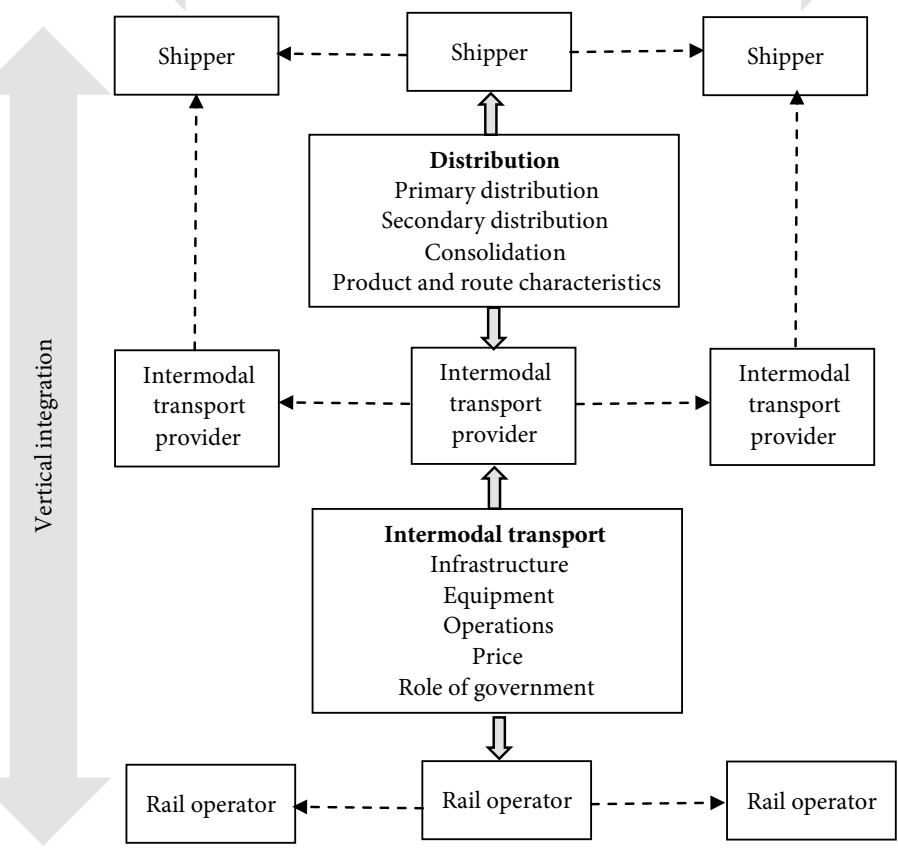


development of consolidation centres or shared user facilities, vendor-managed inventory, better utilisation of transport vehicles and achievement of higher filling rates (Mason et al., 2007).

\section{Research problem outline}

\subsection{Scope of the ChemMultimodal project}

The ChemMultimodal project was focused on a systematic approach to develop and manage sustainable transport. Its main objective was promotion of multimodal transport of chemical goods by coordination and facilitation of cooperation between chemical companies, specialized logistics service providers, terminal operators and public authorities in chemical regions in Central Europe. The project was carried out by fourteen partners from seven countries: Austria, Czech Republic, Germany, Hungary, Italy, Poland and Slovakia, cooperating under the Interreg Central Europe Programme between June 2016 and May 2019. The following points should be underlined among results reached in lifetime of the project: improvement of cooperation and coordination between freight transport stakeholders, identification of common challenges for the promotion of multimodal environmentally friendly freight solutions, development of transnational tool to identify potential for modal shift, increase of intermodal transport by $10 \%$ and reduction of $\mathrm{CO} 2$ emissions by $5 \%$ in cooperation with chemical companies, development of new regular multimodal connections by logistics services providers, advancement of knowledge and capacities of multimodal stakeholders in chemical logistics with its special requirements.

The ChemMultimodal project encompassed three work packages (WP) (Table 1). During the first phase, partners checked the existing situation in the European regions involved and the toolbox was developed to help chemical companies and logistics service providers to facilitate the understanding and application of intermodal transport solutions. In the next step the toolbox was applied in each territory and several companies took part in the project's pilot

\begin{tabular}{ll}
\hline Work package & WP description \\
\hline $\mathrm{WP1}$ & $\begin{array}{l}\text { - Analysis \& Tool Development } \\
\text { Output: Tool for promotion of modal shift of chemical } \\
\text { goods from road to intermodal transport }\end{array}$ \\
\hline $\mathrm{WP2}$ & $\begin{array}{l}\text { - Pilot Testing } \\
\text { Output: Pilot Projects and implementation in each country }\end{array}$ \\
\hline WP3 & $\begin{array}{l}\text { Strategy and Action Plan } \\
\text { Output: Transnational Strategy (1) and Action Plans (7) }\end{array}$
\end{tabular}

Table 1.

ChemMultimodal work packages

Source:

ChemMultimodal project.

- 21 
Barbara Ocicka phase to test innovative transport solutions. Finally, all partners developed transnational strategy and national action plans to recommend some changes and initiatives at national and regional levels.

\subsection{Specificity of logistics in chemical industry}

The chemical industry is an important economic sector in Central Europe with 117 billion EUR turnover and 340.000 employees. Based on the findings of a survey conducted among managers during the Congress of Polish Chemistry 2018 in Wieliczka (Poland), the following global trends will have the most important impact on chemical industry development: $4^{\text {th }}$ industry revolution (30\%), ecological solutions development (26\%), raw materials scarcity $(22 \%)$, mergers \& acquisitions (15\%) and emerging market development (7\%). Chemical companies are important stakeholders responsible for $8 \%$ of freight transport.

Materials and products within the chemical supply chain management require special care in handling, transporting and warehousing. All supply chain parties, including manufacturers, distributors and logistics service providers, must adhere to sophisticated international and national regulations to minimize hazards for process participants and the general society. Increasing tight safety and security regulations have caused a trend towards more outsourcing among chemical manufacturers and their customers. When, chemical companies develop their core competences in R\&D and products manufacturing, logistics service providers offer the expertise required to store and transport potentially dangerous products ensuring safety of logistics operations. LSPs offer chemical shippers both asset and non-asset based logistics services - from finding the best carriers and operating truck fleet or warehouses to development of process innovations and supply chain reconfiguration. A growing number of chemical producers and distributors are collaborating much more with their logistics service providers than they used to do (Elwine, 2018), because LSPs secure capacity in today's tight market. Simultaneously, more and more attention has been focused on the sustainable logistics solutions, like e.g. consolidation of loadings, shift to greener transport modes, maximization of vehicle utilization, multimodal transport and infrastructure development.

Logistics service providers develop their business models taking into account the specificity of chemical supply chains. The evolution of their business models is shown in Figure 3 - from basic through value added to integrated services based on the collaborative outsourcing framework. Table 2 presents both key logistics services and dimensions of supply chain performance delivering value to chemical companies. The performance of chemical supply chains requires increased flexibility to be able to service end markets consistently and higher resilience to mitigate and contain the impact of external disturbances. 


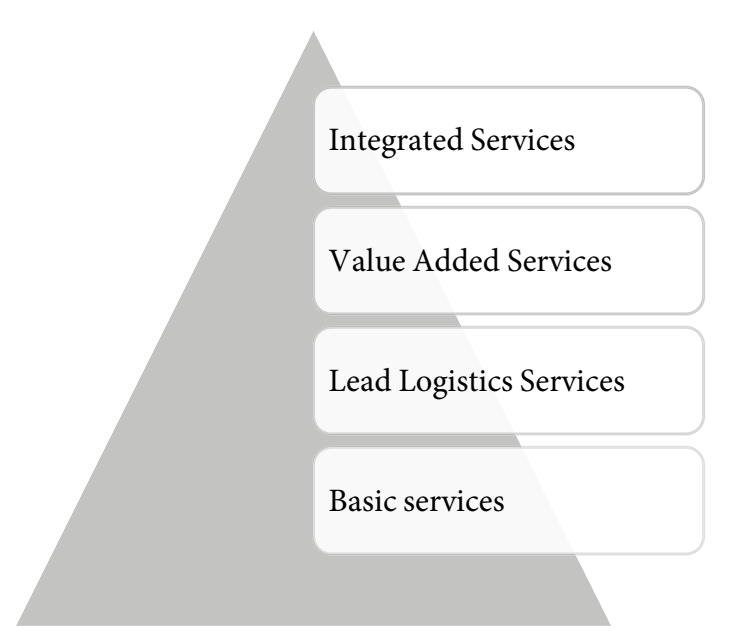

- $\quad$ Shared risk and reward (partnership)

- $\quad$ Strategic relationship value based

- Broad supply chain expertise

- Knowledge and information based

- Advanced technology capability

- Adaptive, flexible and collaborative

- Project management

- Single point of contact

- 3PL integration

- Contract logistics

- Enhanced

- Broader service o囚erings and geographies

- Freight management

- Focused cost reduction

- Niche services

- Transportation execution
THE ROLE OF

LOGISTICS

SERVICE

Barbara Ocicka

Figure 3. Maturity of services and relations within logistics outsourcing models

Source: Cefic and Deloitte, 2001.

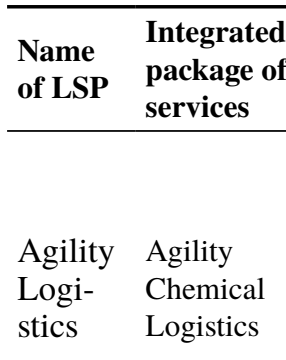

\begin{tabular}{ll}
\hline & \\
BDP & BDP \\
Interna- & Smart \\
tional & Chemical
\end{tabular}

- Expert solutions: commitment to deliver safe, reliable, cost effective supply chain solutions

- Freight forwarding, global platforms and control towers

- Storage and handling: designing, building, operating storage and handling solutions in mature and emerging markets

- Safety management and CSR: dangerous goods consultancy, training and audit services to all sectors involved in the carriage, handling and storage of dangerous goods

- Chemical logistics services: chemical cargo compliance, dangerous goods storage and transportation, documentation and classification, fleet/tank asset management, risk management

- Visibility: order process management, global shipment visibility, tracking, documentation, alerts, KPI reporting and compliance tools, interactive dashboards and maps, ERP integration

- Managed services: benchmarking and consulting

- End-to-end visibility of transport processes supported by the global technology platform and managed TMS services

C.H. ChemSo-

Robin- lutions son
- Delivery assurance and actionable business intelligence that helps minimize risk of transporting hazardous materials

- Responsible ISO14001 practices for safe, responsible and sustainable management of chemicals

- Assuring operational flexibility through support change management
Table 2. Key performance dimensions and services of LSPs

Source: own elaboration based on: https://www. agilitylogistics.com/ EN/Industry-Solutions/ Pages/Chemicals. aspx ?source $=$ Chemicals_ ShortURL (27.07.2018); https://www.chrobinson.

com/en-us/logistics/ industries/chemsolutions/ (24.07.2018); https:// www.dbschenker.com/ ph-en/industry-solutions/ chemicals (27.07.2018);

https://www.logistics. dhl/gb-en/home/industrysectors/chemicals.html (25.07.2018); www. dhl.com/ en/logistics/ industry_sector_ solutions/chemical_ logistics/move_large_ volumes-more_efficiently. html (27.07.2018). 
THE ROLE OF

LOGISTICS

SERVICE

Barbara Ocicka

\begin{tabular}{ll}
\hline $\begin{array}{l}\text { Name } \\
\text { of LSP }\end{array}$ & $\begin{array}{l}\text { Integrated } \\
\text { package of } \\
\text { services }\end{array}$ \\
\hline
\end{tabular}

- Integrated, multimodal transportation concepts, enabling short reaction time and just-in-time delivery in periods of volatile demands

- Special rail offerings such as chem-solution or oil-solution

$\begin{array}{lll}\text { DB } & \text { Chemical } & \text { - Special rail offerings such as chem-solution or oil-solution } \\ \text { Schen- } & \text { Industry } & \text { Responsible handling during transporting hazardous ma- } \\ \text { ker } & \text { Solutions } & \begin{array}{l}\text { terials, ensured with comprehensive safety and emergency } \\ \text { management }\end{array} \\ & & \begin{array}{l}\text { - A variety of } \mathrm{CO}_{2} \text {-saving and climate friendly services, } \\ \text { even } 100 \% \mathrm{CO}_{2} \text { free transport with Eco Plus offer }\end{array} \\ & & \text { - Sensor technology Smartbox }\end{array}$

- Warehousing and order fulfilment

- Packaging, drumming and sample services

- Bulk and packed transport management

$\begin{array}{ll}\text { Deut- } & \text { Chemical } \\ \text { sche } & \text { Solutions } \\ \text { Post } & \text { and Exper- } \\ \text { DHL } & \text { tise } \\ \text { Group } & \end{array}$

- In-plant services

- Supply chain analysis and design

- Overseeing the entire supply chain and its operation

- Controlling material inflow to optimize manufacturing and inventory

- Moving and managing aftermarket parts and materials

- Managing the maintenance, repair and operations supply chain

Table 2. Continued

There are different modern technologies and tools used by LSPs within supply chain management, that should raise in this point of the discussion. C.H. Robinson offers an access to the Navisphere technology platform and TMS services to ensure visibility of the transport processes in the range of the ChemSolutions services package. BDP International provides the BDP Smart Tower application tailored to the chemical industry and ensuring customizable dashboard, an interactive map highlighting to trade lanes and alerts and instant hazardous cargo visibility. Customers can monitor asset locations daily and maximize their utilization or coordinate maintenance and repairs to reduce equipment downtime. Furthermore, DB Schenker offers sensor technology Smartbox for all modes of transport to ensure a detailed overview of freight in an innovative way. This technology guarantees real time tracking via web (24/7), higher level of transparency of the supply chains, potential reduction of customer's logistics and insurance costs and protection against theft, vandalism or other disturbances.

Nowadays, chemical companies develop ecological solutions especially in product development and production management, and do not pay enough attention to environmental responsibility in logistics processes management in supply chains. According to the results of a questionnaire-based survey carried 
out among 21 chemical companies within the first phase of the ChemMultimodal project from July till September 2016, it should be highlighted that the multimodal transport share is low and amounts from 0 to $17 \%$ in supply chains of big chemical companies (Cichosz et al., 2017). Furthermore, results of the survey outlined, that only $15 \%$ of chemical companies and $10 \%$ of logistics service providers measure CO2 emissions derived from logistics management (Cichosz et al., 2016). Among reasons for this measurement status, respondents expressed the following opinions: "we do not have own fleet", "fees for emissions calculations are flat rate", "goods are delivered directly to the customer", "no equipment for measurement", "there is no need or possibility". On the one hand, $23 \%$ of chemical companies and $10 \%$ of LSPs confirmed the willingness to calculate $\mathrm{CO} 2$. Others indicated causes for being not interested in measuring $\mathrm{CO} 2$, such as: "there are no legal requirements", "there is no need", "our system is sufficient". Some respondents declared that they will measure emissions under special conditions, like e.g.: "if government supports" or "if we have some advantage".

While intermodal transport performs very well in terms of sustainability, the following obstacles hinder a more extensive use of intermodal solutions in chemical supply chains:

- costs not competitive in comparison to road transport prevent shifts from road to intermodal solutions;

- missing intermodal connections, especially for France, Spain and Eastern Europe;

- insufficient frequency or capacity of intermodal connections leading to longer transport times in comparison to road transport;

- last mile (on-carriage trucking) solutions insufficient or missing;

- insufficient or missing terminal infrastructure;

- s lack of a consistent implementation strategy at national and EU level to realize more cross border transport;

- insufficient on-time reliability, long transport times;

- $\mathrm{s}$ lack of customer orientation resulting in missing transparency and lack of information (Cefic, 2014).

Based on the findings presented in the Cefic report, to reach the required model the following measures should be taken by different stakeholders involved in intermodal transport:

- Policy and regulations: to enable an increase in cross-border intermodal transport, more international harmonization at technical, legal and organisational level is needed (interoperability);

- Railway companies and infrastructure managers: need to develop a more holistic and international view of the intermodal market, with a more transparent and comparable set of services securing high reliability and competitive prices; 
THE ROLE OF

LOGISTICS

SERVICE

Barbara Ocicka
- Intermodal operators and logistics service providers: need to optimise the transparency of intermodal solutions to their customers and increase collaboration among each other to enable new intermodal connections that are necessary to further push intermodal transport;

- Chemical companies: need to take a more active role in evaluating the most sustainable and efficient mode of transport for each corridor and define expectations and objectives to their respective service providers (Cefic, 2014).

\section{Methodology}

Addressing the need to develop initiatives aiming at better exploitation of intermodal transport in chemical industry, the ChemMultimodal project partners developed a toolbox consisting of four elements.

- Consulting services: offered by the project partners with regards to the following activities: providing information, engaging in discussion, facilitation of cooperation and networking between companies and logistics service providers.

- Planning guidelines: capture necessary transport facts and indicators such as: product type to receive information about the products characteristics, volume to estimate if intermodal transport poses a suitable alternative way of transport, countries crossed along the route with respective driving and loading regulations, bundling options to achieve a more efficient use of capacities and the number of transport units based on the volumes (tons or litres) foreseen for the transport.

- Intermodal Links Planner: allows the visualization of transport scenarios including existing intermodal transport routes, frequency of departure, availability of intermodal network providers and terminal operators, pre- and end-haulage distances.

- CO2 emissions calculator: ensures the one-click calculation of $\mathrm{CO} 2$ emissions from the place of origin to the cargo destination with possibility to define freight characteristics, like: transport distance, weight of goods, mode of transport.

The ChemMultimodal research in the pilots testing phase was based on case studies, in which the environmental impact of modal shifts from road to multimodal transport in chemical supply chains was evaluated in cooperation with chemical companies and logistics service providers. At the beginning, firms identified routes that have a potential for modal shift, next analysed diverse transport scenarios, including opportunities available on the Intermodal Links platform. It was recognized that chemical companies cooperate very closely with LSPs in designing and planning of new routes. Logistics partners ensure knowledge how to integrate transport modes and connections, advise the best 
solution and finally, deliver logistics service value and manage door-to-door transport processes. As a result of the analysis, supply chain partners selected routes for modal shift and tested multimodal solutions in practice. After testing each route, the ChemMultimodal $\mathrm{CO} 2$ calculator was used for evaluation of environmental performance.

\section{Results}

Based on five case studies developed in Poland, focusing on transport modal shifts, it should be underlined, that chemical companies use logistics outsourcing and cooperate closely with logistics service providers in terms of transport planning and management. Based on a good practice analysis of companies participating in the pilot stage, the following pillars of the collaborative planning process might be distinguished:

- agreement on service level and costs of transport outsourcing,

- transferring transport orders by usage of an electronic platform,

- transport operations planning according to the requirements,

- change management in transport operations as a response to a new or modified order.

In case of a new route, planning process usually encompasses:

- designing and analysis of different transport scenarios,

- price comparison taking into account all available transport solutions,

- pilots to test possible transport solutions and compare effects,

- choice of the preferred transport solution.

Considering environmental effects of transport modal shifts realized in cooperation with LSPs, chemical companies achieved reduction of $\mathrm{CO} 2$ emission from $38,7 \%$ to $59,7 \%$. Table 3 presents detailed results of transport modal shifts tested by chemical companies.

\section{Conclusions}

Sustainable supply chain management requires implementation of good and best practices in logistics processes, especially in transport. This article presents a systematic approach to sustainable transport management developed within the ChemMultimodal project, which was focused on promotion of multimodal transport of chemical goods by coordination and facilitation of cooperation between chemical companies, specialized logistics service providers, terminal operators and public authorities in chemical regions in Central Europe.

It was stressed that chemical companies do not pay enough attention to environmental responsibility in logistics processes management. The potential, which is hidden in multimodal solutions development, should be more exploited to deliver chemical goods sustainably, safely and reliably from the origin point to the destination. The ChemMultimodal project's partners had developed the 


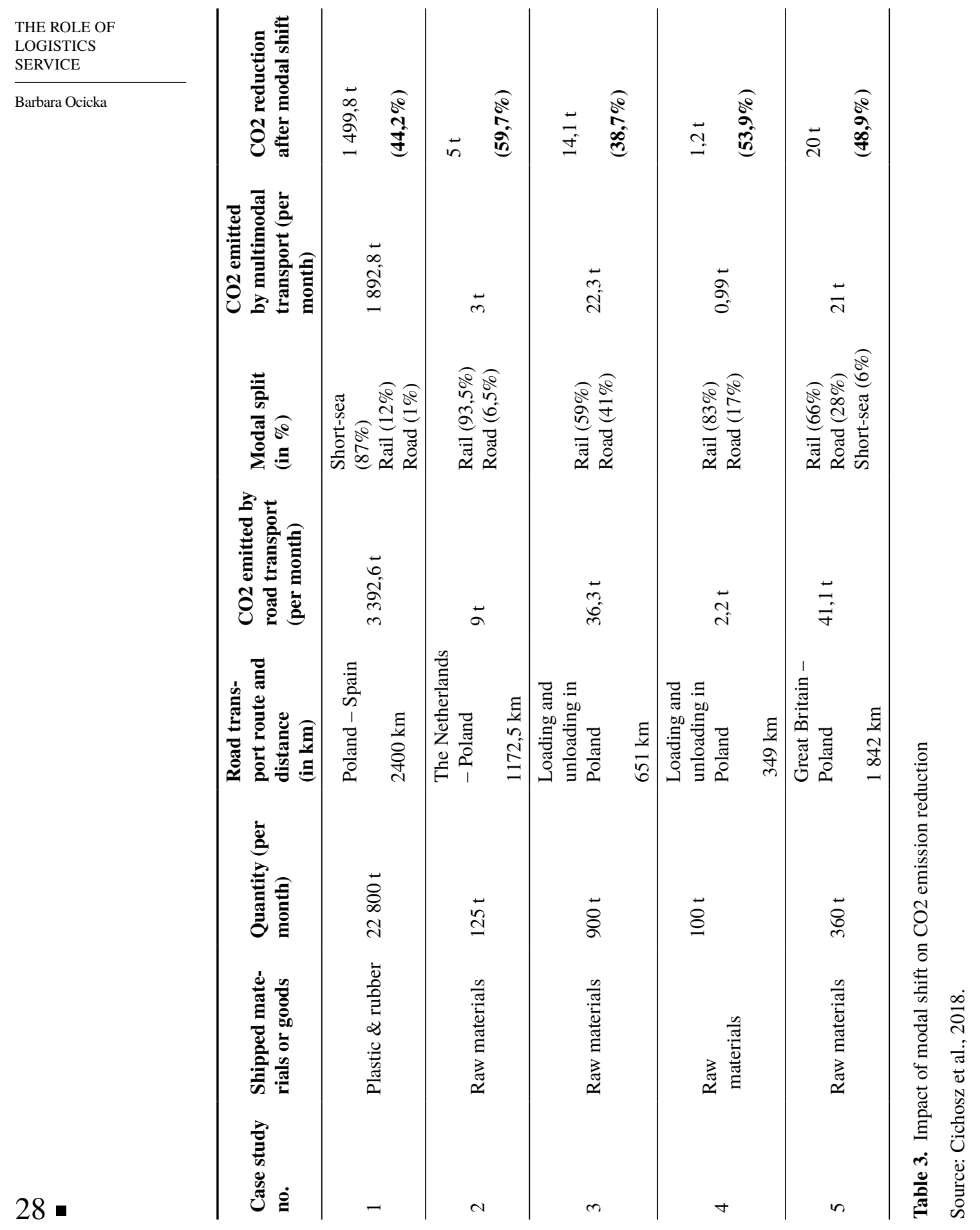


toolbox consisting of four elements, that may support transport modal shifts in chemical supply chains. Especially, the Intermodal Links Planner is useful, because it ensures visibility of different multimodal scenarios and services offered by intermodal network providers. Moreover, the $\mathrm{CO} 2$ emission calculator might be helpful to compare environmental effects of transport processes.

Results of the pilots highlighted that the potential of $\mathrm{CO} 2$ emission reduction amounts to almost $60 \%$. It could be achieved on a regular basis, if logistics service providers will be integrated into environmental responsibility of chemical companies. Logistics partners design, plan and develop multimodal transport processes, coordinating activities and integrating actors and their resources in one system. Their role has become more and more important because of logistics outsourcing development. LSPs advance their offers of logistics services that meet requirements and expectations of clients from chemical industry. Development of low-carbon transport scenarios depends highly on their knowledge and competences.

In the future, an extended analysis might be performed in order to encourage chemical companies on demand side to implement multimodal solutions, and to gain more insight into outcomes of modal shifts. Partners of the ChemMultimodal project developed a transnational strategy and national or regional action plans aiming at further development and improvement of multimodal transport performance.

\section{Notes}

[1] The article is a result of ChemMultimodal Project implementation and is co-financed by Interreg Central Europe Programme.

Scientific work financed from funding for science in the years 2016-2019 granted for the implementation of the co-financed international project.

[2] Further information: www.interreg-central.eu/Content.Node/ChemMultimodal.html.

[3] The calculator is available at: ifs150.mb.uni-magdeburg.de/chemmultimodal/.

[4] The Combined Transport Directive is an EU instrument that aims to reduce the negative sideeffects of goods transport on environment (such as $\mathrm{CO} 2$ and other emissions) and on society (such as, congestion, accidents, noise etc.) also called negative externalities, by supporting the shift from long distance road transport to long distance rail, inland waterways and maritime transport as the latter cause less negative externalities.

\section{References}

Bask, A., Rajahonka, M. (2017), "The role of environmental sustainability in the freight transport mode choice: A systematic literature review with focus on the EU", International Journal of Physical Distribution \& Logistics Management, Vol. 47 No. 7, pp. 560-602. DOI: 10.1108/IJPDLM-03-2017-0127

Carter, R.C., Rogers, D.S. (2008), “A framework of sustainable supply chain management: 
THE ROLE OF LOGISTICS SERVICE

Barbara Ocicka moving toward new theory", International Journal of Physical Distribution \& Logistics Management, Vol. 38, Issue 5, pp. 360-387. DOI: 10.1108/09600030810882816 Cefic (2014), "Cefic Report Intermodal Transport Network Development".

Cefic \& Deloitte (2001), "Chemical Logistics Vision 2020. The next decade's key trends, impacts and solution areas".

Cichosz, M., Nowicka, K., Ocicka, B. (2018), "Collaborative outsourcing for sustainable transport management”, in: Leal Filho, W., Borges de Brito, P.R., Frankenberger, F. (Eds.) International Business, Trade and Institutional Sustainability, Springer, Cham, pp. 709-724. DOI: 10.1007/978-3-030-26759-9_41

Cichosz, M., Nowicka, K., Pluta-Zaremba, A. (2017), "Uwarunkowania wyboru transportu multimodalnego w branży chemicznej w Polsce", Przemyst Chemiczny, No. 96/7, pp. 1435-1439. DOI: 10.15199/62.2017.7.2

Cichosz, M., Nowicka, K., Pluta-Zaremba, A., Susik, M. (2016), "Report on analysis of multimodal transport of chemical goods for the identification of modal shift".

Elwine, A. (2018), "Key logistic trends in the chemical industry".

European Commission (2011), "Roadmap to a Single European Transport Area - Towards a competitive and resource-efficient transport system".

European Commission (2017), "European Council Combined Transport Directive (92/106/ EEC)".

Eurostat, (2018), "Greenhouse gas emission statistics - emission inventories".

Flodén, J., Meers, D., Macharis, C. (2017), "Modelling of intermodal systems", in: Monios, J., Bergqvist, R. (Ed.), Intermodal freight transport and logistics, CRC Press Taylor \& Francis Group, Boca Raton, pp. 213-238. DOI: 10.1201/9781315177762-16

Grant, D.B., Trautrims, A., Wong, Ch.Y. (2015), Sustainable Logistics and Supply Chain Management, KoganPage, Croydon.

Macharis, C., Vanhaverbeke, L., Van Lier, T., Pekin, E., Meers, D. (2012), "Bringing intermodal transport to the potential customers: An interactive modal shift website tool", Research in Transportation Business and Management, Vol. 5, pp. 67-77. DOI: $10.1016 /$ j.rtbm.2012.11.005

Mason, R., Lalwani, Ch., Boughton, R. (2007), "Combining vertical and horizontal collaboration for transport optimisation”, Supply Chain Management: An International Journal, Vol. 12 No. 3, pp. 187-199. DOI: 10.1108/13598540710742509

Monios, J., Bergqvist, R. (2017), "Intermodal logistics", in: Monios, J., Bergqvist, R. (Eds.), Intermodal freight transport and logistics, CRC Press Taylor \& Francis Group, Boca Raton, pp. 169-193. DOI: 10.1201/9781315177762-9

Pålsson, H., Johansson, O. (2016), "Reducing transportation emissions: Company intentions, barriers and discriminating factors", Benchmarking: An International Journal, Vol. 23 No. 3, pp. 674-703. DOI: 10.1108/bij-03-2014-0025

Sutherland, J. (2003), “Collaborative Transport Management”, Business Briefing, Transport and Logistics Packaging, pp. 88-91.

U.S. Department of State (2016), "2016 Second Biennial Report of the United States of America".

World Commission on Environment and Development (1987), "Report of the World Commission on Environment and Development". 
World Economic Forum, (2009), "Supply chain decarbonisation. The role of logistics and transport in reducing supply chain carbon emissions".

https://www.agilitylogistics.com/EN/IndustrySolutions/Pages/Chemicals. aspx ?source=Chemicals_ShortURL (accessed 27 June 2018).

https://www.chrobinson.com/en-us/logistics/industries/chemsolutions/ (accessed 24 June 2018).

https://www.dbschenker.com/ph-en/industry-solutions/chemicals (accessed 27 June 2018). https://www.logistics.dhl/gb-en/home/industry-sectors/chemicals.html (accessed 25 July 2018).

www.dhl.com/en/logistics/industry_sector_solutions/chemical_logistics/move_large_volumes-more_efficiently.html (accessed 27 July 2018). 